\title{
Intraseasonal Effects of El Niño-Southern Oscillation on North Atlantic Climate
}

\author{
BlancA AyARZAgüEnA \\ Department of Mathematics, University of Exeter, Exeter, United Kingdom, and Departamento de Física de la \\ Tierra y Astrofísica, Universidad Complutense de Madrid, and Instituto de Geociencias, Consejo Superior de \\ Investigaciones Científicas-Universidad Complutense de Madrid (CSIC-UCM), Madrid, Spain
}

SARAH INESON AND NiCK J. DUNSTONE

Met Office Hadley Centre, Exeter, United Kingdom

MARK P. BALDWIN

Department of Mathematics, University of Exeter, United Kingdom

ADAM A. SCAIFE

Department of Mathematics, University of Exeter, and Met Office Hadley Centre, Exeter, United Kingdom

(Manuscript received 23 February 2018, in final form 18 July 2018)

\begin{abstract}
It is well established that El Niño-Southern Oscillation (ENSO) impacts the North Atlantic-European (NAE) climate, with the strongest influence in winter. In late winter, the ENSO signal travels via both tropospheric and stratospheric pathways to the NAE sector and often projects onto the North Atlantic Oscillation. However, this signal does not strengthen gradually during winter, and some studies have suggested that the ENSO signal is different between early and late winter and that the teleconnections involved in the early winter subperiod are not well understood. In this study, we investigate the ENSO teleconnection to NAE in early winter (November-December) and characterize the possible mechanisms involved in that teleconnection. To do so, observations, reanalysis data and the output of different types of model simulations have been used. We show that the intraseasonal winter shift of the NAE response to ENSO is detected for both El Niño and La Niña and is significant in both observations and initialized predictions, but it is not reproduced by free-running Coupled Model Intercomparison Project phase 5 (CMIP5) models. The teleconnection is established through the troposphere in early winter and is related to ENSO effects over the Gulf of Mexico and Caribbean Sea that appear in rainfall and reach the NAE region. CMIP5 model biases in equatorial Pacific ENSO sea surface temperature patterns and strength appear to explain the lack of signal in the Gulf of Mexico and Caribbean Sea and, hence, their inability to reproduce the intraseasonal shift of the ENSO signal over Europe.
\end{abstract}

\section{Introduction}

El Niño-Southern Oscillation (ENSO) impacts the climate of the whole globe and affects remote areas including the North Atlantic-European sector (NAE; Peixoto and Oort 1992; Davey et al. 2014). The canonical ENSO signal in NAE is typically detected in late winter and resembles a negative (positive) phase of the North Atlantic Oscillation (NAO) for El Niño (La Niña) conditions (e.g., Brönnimann 2007). The teleconnections

Corresponding author: Blanca Ayarzagüena, bayarzag@ucm.es are established through various pathways involving both the stratosphere and the troposphere. The tropospheric teleconnections imply mechanisms where the North Pacific region or the tropical North Atlantic play the main role (e.g., Brönnimann 2007). The first one refers to the intensification of the Pacific-North America (PNA) pattern through the Rossby wave propagation from the tropical Pacific (Horel and Wallace 1981). The second one may occur through atmospheric perturbation of the tropical North Atlantic area through the disturbance of the Walker and the Atlantic Hadley cells (Wang 2002), the propagation 
of a Kelvin wave front induced by the ENSO-related heating in the equatorial Pacific (Lin et al. 2007), or a secondary Gill-type structure in the tropical Atlantic (García-Serrano et al. 2017). The ENSO-associated sea surface temperature (SST) changes in the tropical North Atlantic could also impact the European climate through Rossby wave propagation (Toniazzo and Scaife 2006; Ham et al. 2014). As for the stratospheric pathway, the perturbation of the Aleutian low interferes constructively with the upward-propagating stationary wave 1 during El Niño (EN), causing an intensification of this wave and a subsequent deceleration of the stratospheric polar vortex (Manzini et al. 2006). The resulting stratospheric circulation anomalies propagate downward (e.g., García-Herrera et al. 2006; Ineson and Scaife 2009; Cagnazzo and Manzini 2009). The opposite happens for La Niña (LN) conditions, particularly for strong events (Iza et al. 2016). Very recently, Jiménez-Esteve and Domeisen (2018) have also shown that the tropospheric and stratospheric pathways in late winter work together and the stratosphere can alter the ENSO tropospheric pathway to Europe.

In early winter the ENSO signal in NAE is different from that in late winter (Moron and Gouirand 2003; Brönnimann et al. 2007; Fereday et al. 2008; Bladé et al. 2008; Ineson and Scaife 2009; King et al. 2018a). However, the response in early winter is weaker than in the following months, and so much less effort has been put on trying to understand this signal. Only a few studies have addressed the topic but have not identified a clear mechanism (Bladé et al. 2008; Ineson and Scaife 2009; King et al. 2018a,b). Bladé et al. (2008) focused on the North Pacific response to ENSO in late fall and found a modulation of the signal by SSTs in the tropical west Pacific (TWP). However, their observational results are not reproduced in model simulations and the relationship between the SST variability over the TWP and ENSO is unclear. Ineson and Scaife (2009) examined the stratospheric pathway to connect the ENSO signal to the NAE atmospheric circulation. They identified a shift in the sign of the NAO and the interference of anomalous and climatological waves in observations from early to late winter, but their study was mainly focused on late winter. King et al. (2018a) highlighted the ENSO teleconnections to the northern extratropics in early winter but with a special focus on their multidecadal variability. They found the ENSO signal over NAE in early winter occurred throughout the last century. More recently, King et al. (2018b) examined these ENSO teleconnections in observations and seasonal hindcasts in early winter and showed the relevant impact of this teleconnection on European climate in November.
However, these authors did not diagnose mechanisms or pathways for the ENSO signal to travel to Europe. In fact, this is one of the questions that King et al. (2018b) listed as a topic that required future analysis.

In this study, we investigate the ENSO teleconnection to NAE in early winter and aim to explain for the first time the possible mechanisms involved in that teleconnection. We use observational data and seasonal hindcasts as King et al. (2018b), but we also extend the analysis to free-running coupled-model simulation output. First, we present the ENSO signal in NAE in the different datasets. Next, we check the stratospheric and tropospheric pathways that might be involved in that teleconnection. Correct representations of this teleconnection could improve the seasonal forecast of early winter European climate in the same way as it has been recently established in late winter at seasonal (e.g., Scaife et al. 2014) and interannual (Dunstone et al. 2016) time scales.

\section{Data and methodology}

We use observed sea level pressure (SLP) data from HadSLP2 (Met Office Hadley Centre 2005; Allan and Ansell 2006) from 1873 to 2015, JRA-55 data extending from 1958 to 2016 for other atmospheric fields (Japan Meteorological Agency 2013; Kobayashi et al. 2015), and HadISST (Rayner et al. 2003; Met Office Hadley Centre 2003) for SST from the common periods to the respective atmospheric fields. We also analyze output from initialized and free-running climate models. In particular, we have examined an ensemble of hindcast simulations from the GloSea5 Met Office global seasonal forecast system (MacLachlan et al. 2015). The hindcasts correspond to the period 1993-2015 (23 years) and were initialized on 25 September, 1 October, and 9 October. There are 10 ensemble members for each start date, giving a total ensemble size of 30 members for each year. The underpinning climate model is the Met Office global coupled model HadGEM3-GC2. This model has been shown to have good representation of the modes of climate variability, including ENSO (Williams et al. 2015). The vertical resolution is 85 levels in the atmosphere (with a top at $85 \mathrm{~km}$ ) and 75 levels in the ocean (with a 1-m top level). The ocean horizontal resolution is $0.25^{\circ}$ on a tripolar grid and in the atmosphere a horizontal resolution of $\mathrm{N} 216$ (60 km in midlatitudes) is used. In addition, the output of simulations under preindustrial conditions (PiCTRL) of some high-top models contributing to phase 5 of the Coupled Model Intercomparison Project (CMIP5) has also been used (see Table 1 for more details). 
TABLE 1. CMIP5 high-top models used in this study.

\begin{tabular}{lccll}
\hline \multicolumn{1}{c}{ Models } & No. of years & $\begin{array}{c}\text { Horizontal resolution } \\
(\text { lat } \times \text { lon })\end{array}$ & $\begin{array}{c}\text { Vertical levels } \\
(\text { nominal top; hPa })\end{array}$ & \multicolumn{1}{c}{ References } \\
\hline CESM1(WACCM) & 200 & $1.9^{\circ} \times 2.5^{\circ}$ & $66\left(5 \times 10^{-6}\right)$ & Hurrell et al. (2013) \\
CMCC-CESM & 275 & $3.4^{\circ} \times 3.8^{\circ}$ & $39(0.01)$ & Vichi et al. (2011); Manzini et al. (2012) \\
CMCC-CMS & 500 & $3.7^{\circ} \times 3.8^{\circ}$ & $95(0.01)$ & Fogli et al. (2009); Manzini et al. (2012) \\
INM-CM4.0 & 500 & $1.5^{\circ} \times 2^{\circ}$ & $21(0.1)$ & Volodin et al. (2010) \\
IPSL-CM5A-LR & 1000 & $1.9^{\circ} \times 3.8^{\circ}$ & $39(0.04)$ & Dufresne et al. (2013) \\
MIROC-ESM-CHEM & 250 & $2.8^{\circ} \times 2.8$ & $80(0.003)$ & Watanabe et al. (2011) \\
MPI-ESM-LR & 1000 & $1.9^{\circ} \times 1.9^{\circ}$ & $47(0.01)$ & Giorgetta et al. (2013) \\
MRI-CGCM3 & 500 & $1.1^{\circ} \times 1.1^{\circ}$ & $48(0.01)$ & Yukimoto (2011) \\
\hline
\end{tabular}

We created composite maps of different variables for EN and LN events in early winter [NovemberDecember (ND)] and late winter [January-February (JF)]. EN events are identified when the Niño-3.4 index in December-February (DJF) exceeds $+0.8 \mathrm{~K}$; $\mathrm{LN}$ events correspond to a drop of this index below $-0.8 \mathrm{~K}$. The $0.8-\mathrm{K}$ threshold is close to $0.83 \mathrm{~K}$, the standard deviation for the observed temperature anomalies in the Niño-3.4 region in the period 1951-2000. The results for the ENSO signal over NAE region in early winter are not sensitive to the threshold of Niño-3.4 index for the selection of events.

Observational data are not detrended, and results do not change when the linear trend is removed. In this sense, conclusions derived for free-running models are not modified either when repeating the analysis for CMIP5 historical runs (not shown). Anomalies are computed based on a climatology for the complementary set of years in neutral ENSO conditions. Statistical significance of EN and LN anomalies has been computed applying Student's $t$ test for large samples (SLP observations and GloSea5 simulations) and Monte Carlo test for smaller samples (JRA-55 data). Model data have been regridded to a common $\mathrm{T} 42$ grid before computing multimodel means.

Rossby wave source (RWS) magnitude and the tracing of ray paths of Rossby waves have been used to analyze the tropospheric teleconnections of ENSO to the North Atlantic area. RWS is defined by as (Sardeshmukh and Hoskins 1988)

$$
\mathrm{RWS}=-\nabla \cdot\left(\mathbf{v}_{\chi} \zeta\right)=-\left(\zeta \nabla \cdot \mathbf{v}_{\chi}+\mathbf{v}_{\chi} \cdot \nabla \zeta\right),
$$

where $\mathbf{v}_{\chi}$ is the divergent component of the horizontal wind and $\zeta$ is the absolute vorticity.

For ray tracing, we have applied the same algorithm as Scaife et al. (2017). In particular, we have computed the two components of the group velocity $\left(c_{g x}, c_{g y}\right)$ of stationary planetary Rossby waves according to Eqs. (2a) and ( $2 \mathrm{~b})$, respectively, for a specific location and then, stepped forward by $2 \mathrm{~h}$ to calculate the new location of the ray and the corresponding group velocity at the new location. We have repeated the same operation for up to 10 days $(240 \mathrm{~h})$ :

$$
\begin{aligned}
c_{g x} & =\frac{2 \bar{u}^{2} k^{2}}{\left(\beta-\bar{u}_{y y}\right)}, \\
c_{g y} & =\frac{2 \bar{u}^{2} k\left(\frac{\beta-\bar{u}_{y y}}{\bar{u}}-k^{2}\right)^{1 / 2}}{\left(\beta-\bar{u}_{y y}\right)},
\end{aligned}
$$

where $k$ is the zonal wavenumber $(2 \pi$ divided by wavelength), $\beta$ is the meridional gradient of the Coriolis parameter, $u$ is the climatological mean zonal wind, and $u_{y y}$ is its second derivative in the meridional direction. The overbar in $u$ and $u_{y y}$ denotes a $60^{\circ}$ zonal average as in Scaife et al. (2017) and was selected to represent the wind on a typical wave scale.

\section{Results}

First, we show the response of the North Atlantic circulation in early and late winter in different datasets. Second, we focus on the early winter signal and examine the possible pathway for this signal to travel from the equatorial Pacific to Europe.

\section{a. North Atlantic circulation response to ENSO}

Figure 1 shows EN and LN composite maps of anomalous SLP of HadSLP2 dataset for the period 1873-2015 for early and late winter. The signal in SLP in early winter is quite different from that in late winter for both EN and LN events. In early winter and under EN conditions, it has a wavelike structure with three important centers of negative SLP anomalies-one over Alaska and the Aleutian Islands, another one in the North Atlantic, and the third over Siberia (Fig. 1a) -in agreement with King et al. (2018b). In contrast, the EN pattern in late winter resembles the negative phase of the annular mode with positive SLP anomalies over the pole and negative anomalies at midlatitudes, although 
a) EN ND

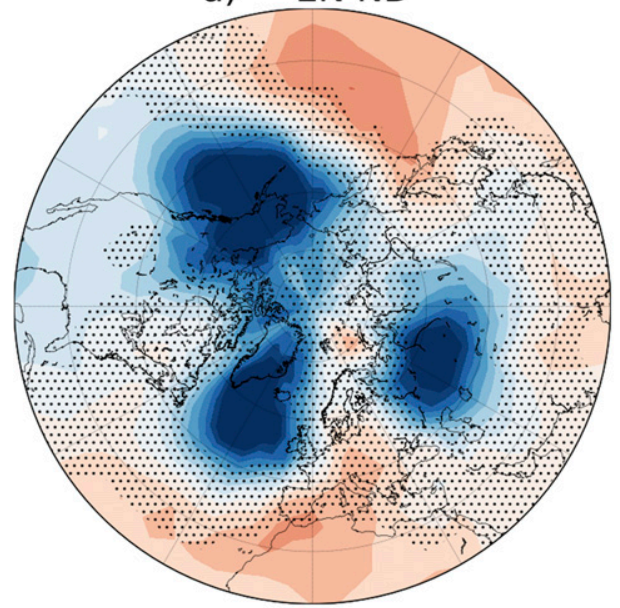

c) LN ND

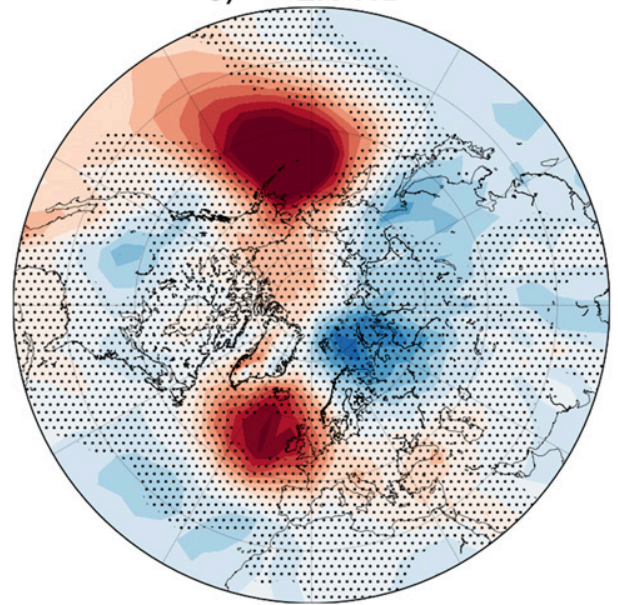

b) EN JF

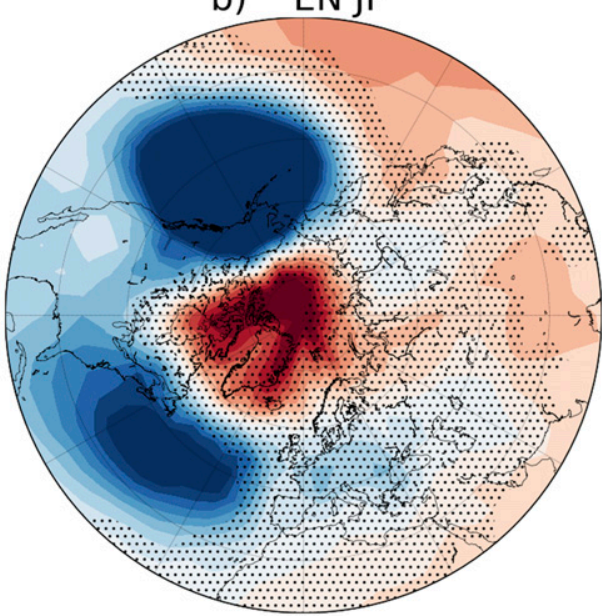

d) LN JF

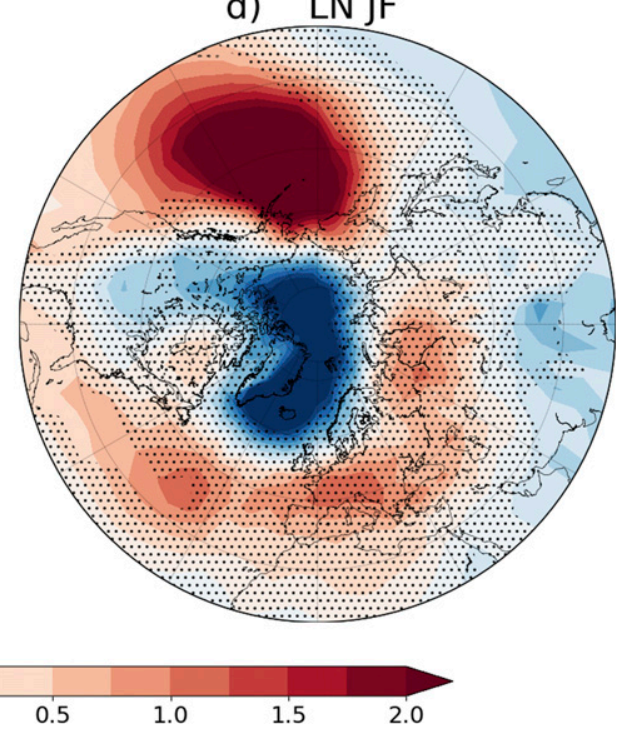

FIG. 1. Different early and late winter NAE responses to ENSO: composite map of anomalous mean SLP of HadSLP2 for EN events in (a) early winter (ND) and (b) late winter (JF). (c),(d) As in (a) and (b), but for LN events. Contour interval is $0.25 \mathrm{hPa}$. Nonstippled areas represent statistically significant values at a $95 \%$ confidence level (Student's $t$ test).

only statistically significant in the Western Hemisphere (Fig. 1b). The annular structure is consistent with the stratospheric contribution in this late winter subperiod (e.g., Ineson and Scaife 2009). Since the North Pacific center of negative anomalies is common to the SLP response to EN in both winter subperiods, the main difference between them is then primarily found over the Atlantic. Notice that the center of action of both patterns in that region is located upstream of Europe, so it is expected to impact precipitation and surface air temperature through changes in the Atlantic wind signal as shown in Fereday et al. (2008). For LN events, we obtain similar SLP patterns to those of EN conditions but of opposite sign, except for the center of anomalies over
Siberia in early winter that is not present in this ENSO phase (Figs. 1c,d). Most of the mentioned SLP anomalies are statistically significant at the $95 \%$ confidence level, meaning that the response is robust for both EN and LN phases. LN figures show a lower extension of areas with statistically significant values, particularly at midlatitudes, presumably because the anomalies are weaker than in EN. In late winter the occurrence of a fair number of stratospheric sudden warmings (SSWs) during some LN events might at least partly explain the weaker anomalies, as their tropospheric fingerprint would cancel out the positive annular mode pattern (Polvani et al. 2017). Nevertheless, Deser et al. (2017) recently showed that asymmetries between EN and LN 
a) EN ND

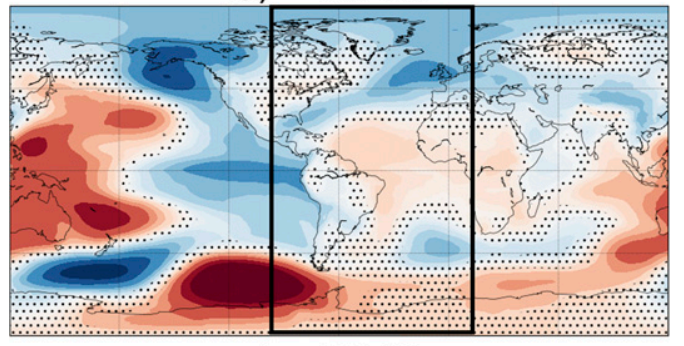

c) LN ND

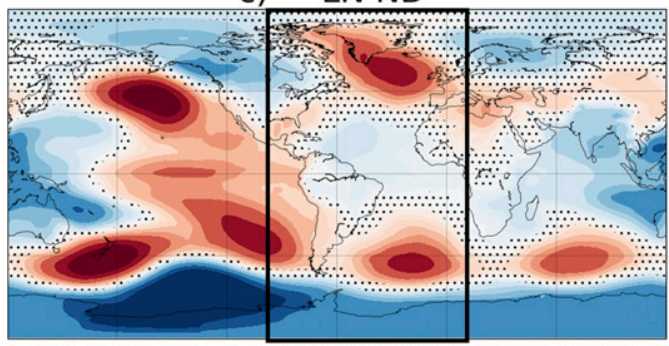

b) EN JF

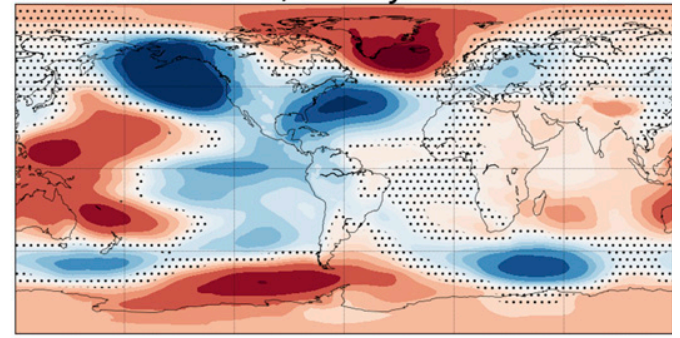

d) LN JF

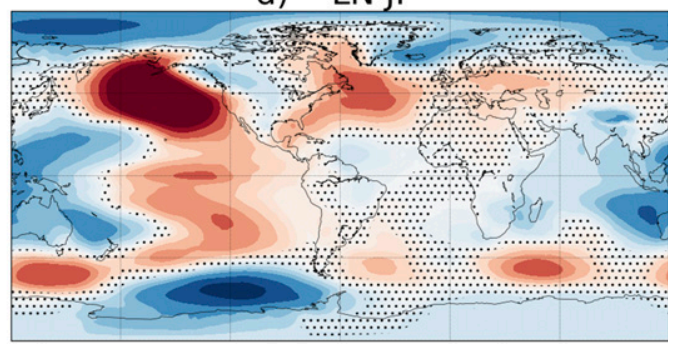

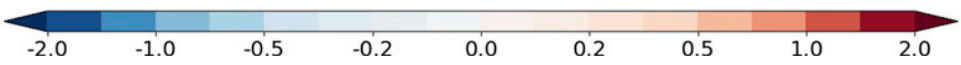

FIG. 2. Symmetric and asymmetric interhemispheric Atlantic response to ENSO in early and late winter, respectively. As in Fig. 1, but for GloSea5 seasonal predictions. The color interval is not linear: $\pm 0.1, \pm 0.2, \pm 0.3$, $\pm 0.5, \pm 0.75, \pm 1, \pm 1.5$, and $\pm 2 \mathrm{hPa}$.

events in SLP extratropical response in winter (DJF) are not statistically significant based on the application of random sampling techniques. Similar results are found for JRA-55 (not shown), although the regions of statistical significance are smaller than in observations, probably due to the shorter reanalysis data record.

Initialized seasonal predictions reproduce the early to late winter transition found in observations at a lead time of 2-5 months (Fig. 2). Since the period covered by these predictions is relatively short (23 years), we have checked the reproduction of this transition in hindcast simulations of the Met Office Decadal Prediction System (DePreSys3; Dunstone et al. 2016) that extend for a longer period (1981-2016) and use the same climate model (HadGEM3-GC2; not shown). This verification confirms the GloSea5 results. The good agreement with observations suggests that the intraseasonal signals are robust. Further evidence of a tropical (ENSO) origin of these anomalies can be found in the global projection of Fig. 2, where an interhemispheric symmetry of the signal for EN and LN events about the equator in the Atlantic basin is seen in early winter (black box in Figs. 2a,c). Note though that this interhemispheric symmetry is absent in late winter due to different reasons. First, the ENSO stratospheric pathway to the North Atlantic is strong in late winter (e.g., Ineson and Scaife 2009; Butler et al. 2014), whereas the ENSO stratospheric anomalies in the Southern Hemisphere tend to attenuate from
October, and so its influence on the tropospheric circulation in boreal winter might be small (Lin et al. 2012; Zubiaurre and Calvo 2012). Second, background winds in late winter show a larger interhemispheric asymmetry than in early winter. The same interhemispheric symmetry in early winter SLP is also observed in HadSLP2 and JRA-55.

This global view also helps us to identify potential tropospheric pathways followed by the signal in early winter. Indeed, two apparent possibilities arise. One would involve a wave train originating over the west Pacific that propagates poleward and eastward to the Atlantic. A similar wave train might be expected in the Southern Hemisphere too. The second possibility is an interbasin effect in the deep tropics and then wave trains describing an arch propagating from the subtropical North and South Atlantic, northward and southward to northern and southern extratropics, respectively. We will explore these possible pathways in section $3 \mathrm{~b}$.

We have also examined the early and late winter teleconnection in free-running, coupled-model CMIP5 preindustrial runs (Fig. 3). In late winter, models reproduce an annular mode pattern similar to observations and hindcast runs (Figs. 3b,d). In contrast, the modeled early winter pattern over the Atlantic is different from observations, and models simulate a weakened version of the late winter pattern (Figs. 3a,c), even when only considering November (not shown). 
a) EN ND

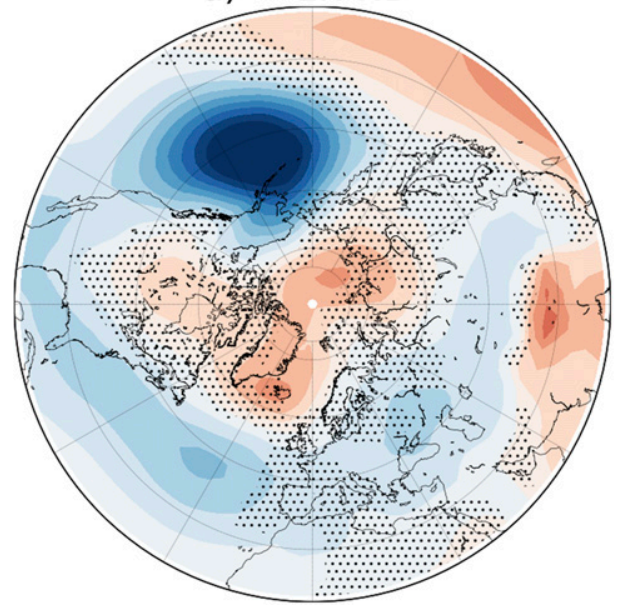

c) LN ND

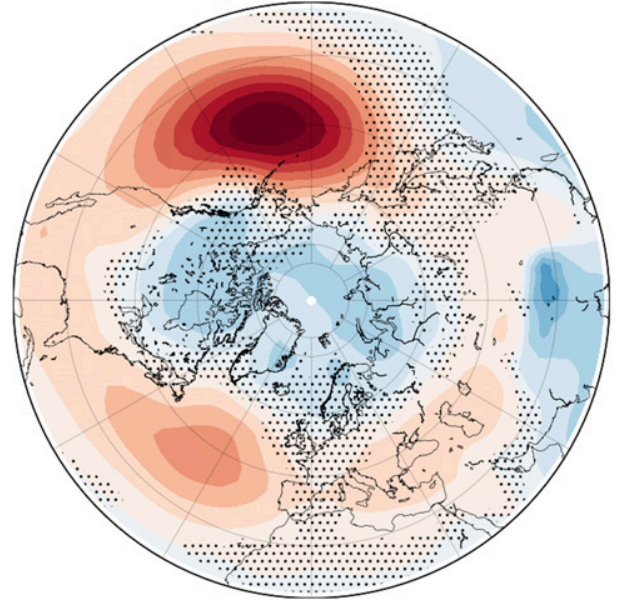

b) EN JF

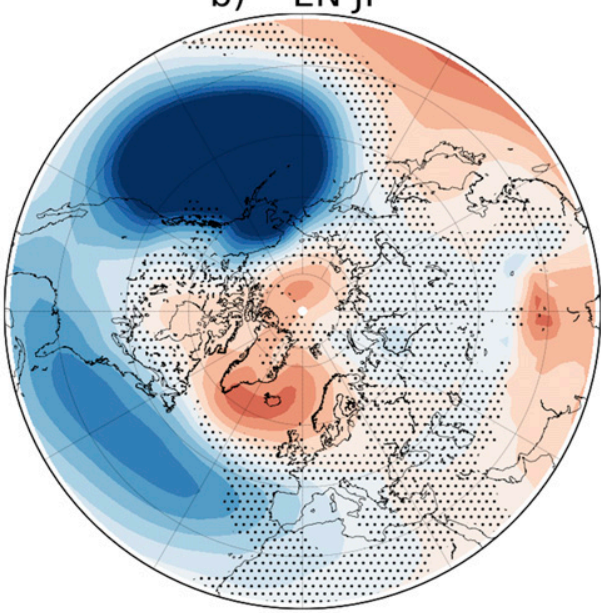

d) LN JF

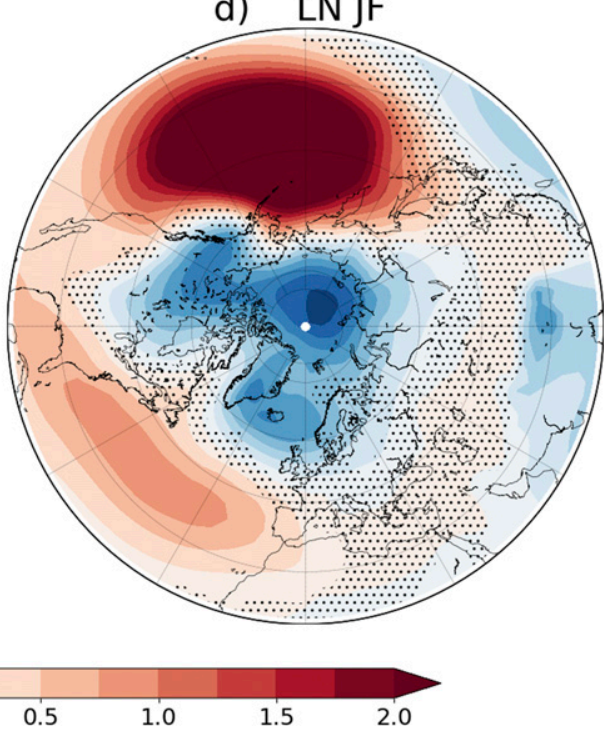

FIG. 3. Free-running CMIP5 models do not reproduce the early and late winter difference in ENSO teleconnections to NAE. As in Fig. 1, but for the multimodel mean of ENSO events in CMIP5 PiCTRL simulations of different high-top models. Nonstippled areas indicate where at least $75 \%$ of models agree on sign with the multimodel mean.

This last result suggests that some of the processes involved in the teleconnection of the ENSO signal to Europe in early winter may not be well simulated in CMIP5 models.

\section{b. Pathways of the ENSO signal to North Atlantic in early winter}

To understand the teleconnection of the ENSO signal to North Atlantic in early winter we have checked potential tropospheric and stratospheric pathways.

First, we explore the possibility of a stratospheric bridge similar to the mechanism that, in late winter, connects the ENSO signal to the Euro-Atlantic atmospheric circulation (e.g., Bell et al. 2009; Ineson and
Scaife 2009; Cagnazzo and Manzini 2009; Butler et al. 2014). Figure 4a presents the EN-minus-LN differences of JRA-55 monthly anomalies of the stratospheric zonal-mean zonal wind at $10 \mathrm{hPa}$ and $60^{\circ} \mathrm{N}$, commonly used as a measure of the polar night jet (PNJ) strength. Only in late winter, and more specifically in February, are differences between EN and LN large and statistically significant in agreement with previous studies (e.g., Manzini et al. 2006). These differences in January and February are even larger for ENSO events that satisfy the threshold of $\pm 1 \mathrm{~K}$ (not shown). This agrees well with Iza et al. (2016), who report that only the signal of strong LN events in the polar stratosphere can be seen over other sources of variability. In contrast, in early winter 

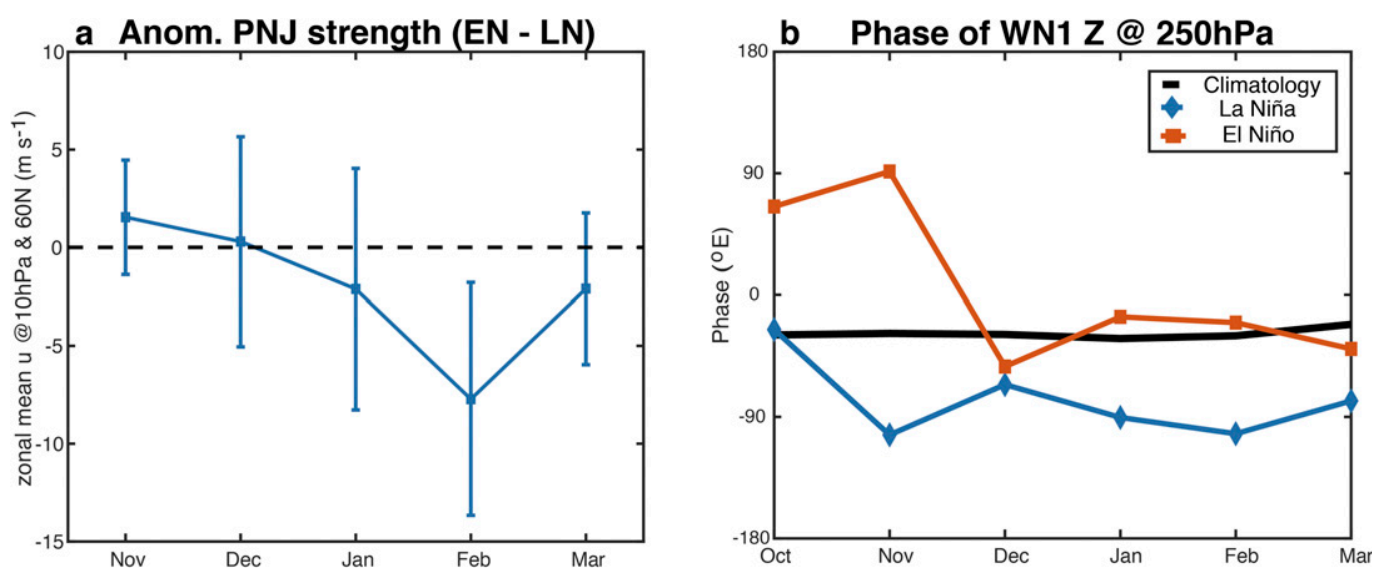

FIG. 4. Stratosphere is only active in late winter. (a) El Niño minus La Niña difference in the anomalous zonalmean zonal wind at $60^{\circ} \mathrm{N}$ and $10 \mathrm{hPa}$ in JRA-55 (m s$\left.{ }^{-1}\right)$. Error bars show the standard error. (b) Phase of WN1 component of climatological wave (black line) and anomalous wave for LN years (blue line) and for EN years (red line) of geopotential height at $250 \mathrm{hPa}$ averaged over $40^{\circ}-60^{\circ} \mathrm{N}$.

(ND) the anomalous PNJ strength does not differ much between EN and LN.

An analysis of the interaction of upward-propagating ENSO-related anomalous and climatological wavenumber-1 (WN1) waves of extratropical geopotential height through the depth of the troposphere and stratosphere agrees well with the PNJ strength results. Figure $4 \mathrm{~b}$ displays the phases of climatological and anomalous WN1 waves of $Z$ at $250 \mathrm{hPa}$ (close to the tropopause). In EN case, anomalous and climatological waves are in quadrature in late autumn (October-November), indicating no interaction between them, and in phase from December on (i.e., constructive interference). As for LN, they are in quadrature in all winter months (not in October), but when focusing on strong events (threshold of Niño-3.4 index: $\pm 1 \mathrm{~K}$ ), they interfere destructively in late winter (not shown). This would again support the results of Iza et al. (2016), who documented that the stratospheric pathway of LN is only clearly identified for strong events in late winter. Thus, since this is the mechanism explaining the ENSO impact on Atlantic surface climate via the stratosphere (e.g., Ineson and Scaife 2009), the lack of planetary wave interference and lack of stratospheric zonal wind signal support the idea that the stratosphere does not play a role in the ENSO teleconnection in early winter.

Given that the stratospheric pathway does not appear to be active in early winter, we examine tropospheric pathways of the ENSO signal instead. To do so, we have searched for anomalous sources of Rossby wave activity in ND associated with ENSO (Figs. 5a,b). In Fig. 5a, we identify two statistically significant anomalous RWS in JRA-55 that could feasibly generate waves propagating into the North Atlantic, one in the Gulf of Mexico and southern United States and a second in the northwestern Pacific for EN events. These two anomalous RWS have large amplitude and also agree well with the origin of the two different tropospheric pathways that we suggested when looking at the SLP composites of Fig. 2. However, the ray paths for linear Rossby waves calculated from both locations show that only perturbations originating over the Gulf of Mexico and, more likely, those of zonal wavenumber 3 , follow a track that connects with the anomalous cyclonic center south of Greenland (yellow contours in Fig. 5a). This negative anomaly in the upper tropospheric streamfunction corresponds to the negative SLP anomaly over the Atlantic in Figs. 1a and 2a. Please note that we are using a simple linear ray-tracing algorithm that only represents qualitatively the wave propagation, and so we should be cautious about overinterpreting these results (Scaife et al. 2017). The sign changes with the phase of ENSO and anomalous RWSs of opposite sign are found for LN events in the same locations (Fig. 5b). Similarly to EN conditions, Rossby wave trains originating over the Gulf of Mexico pass through the center of positive streamfunction anomalies over the North Atlantic (yellow contours in Fig. 5b), and the sign reversal of RWS anomalies in the two cases is consistent with the reversal in the sign of the early winter teleconnection in Figs. 1 and 2. In Figs. 5a and 5b, a third anomalous RWS is distinguished over the central tropical Pacific. However, the anomalies are weaker than in the other two and the ray tracing shows unlikely a link between the perturbations originating there and the circulation anomalies over the North Atlantic (not shown to avoid confusion in the plot). Figures $5 \mathrm{a}$ and $5 \mathrm{~b}$ also include the ray tracing for waves exiting the RWS to the east of the Uruguay coast 

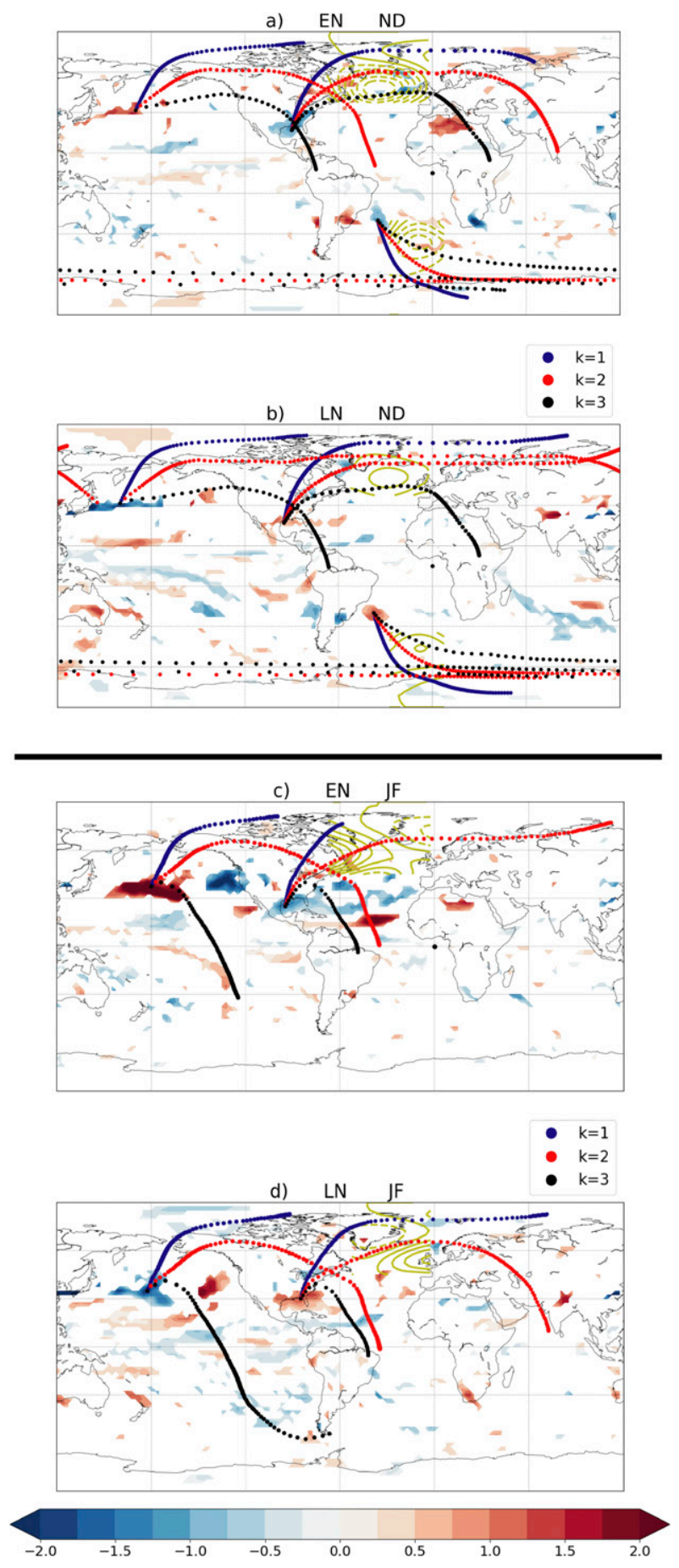

FIG. 5. Rossby wave sources in Gulf of Mexico enable propagation to the North Atlantic in early winter. (a) Composite maps of anomalous RWS $\left(\times 10^{-11} \mathrm{~s}^{-2}\right)$ at $200 \mathrm{hPa}$ in ND for EN events in JRA-55. Only statistically significant anomalies at $95 \%$ confidence level are plotted. (b) As in (a), but for LN events. (c),(d) As in (a) and (b), but for JF. Dots of different colors denote example rays of Rossby waves of zonal wavenumbers 1 (blue line), 2 (red line), and 3 (black line) starting from major sources. Thick yellow lines indicate zonally asymmetric component of the streamfunction at $200 \mathrm{hPa}$ in the Atlantic region. and reaching the South Atlantic circulation anomalies that are symmetric to the North Atlantic ones. The location of the Southern Hemisphere RWS and the ray tracing are also in agreement with the idea of the interbasin effect in the tropics and the subsequent propagation of a wave train from the Atlantic subtropics to the extratropics. However, since the analysis of ENSO teleconnections in the Southern Hemisphere is out of the scope of this manuscript, we will only focus on the Northern Hemisphere in the rest of the analysis.

There is considerable evidence in the literature (e.g., Ineson and Scaife 2009; Cagnazzo and Manzini 2009; Butler et al. 2014) indicating that the late winter NAE response to ENSO is primarily due to changes in the stratospheric circulation, and that this gives rise to the intraseasonal shift. However, as indicated in section 1, we do not rule out the possibility that tropospheric pathways may also play a role, and so we have examined the RWS anomalies associated with EN and LN events in JF too (Figs. 5c,d). In late winter, the anomalous RWS over the Gulf of Mexico is still present for both EN and $\mathrm{LN}$ as in early winter. However, unlike in ND, there is not a center of streamfunction anomalies over the North Atlantic area where we identified the circulation anomalies in ND (in yellow contours). This could be due to a combination of different factors. First, as indicated before, the stratospheric contribution might be masking at least partially the tropospheric signal. Second, the source over the North Pacific becomes much stronger in late winter, while this is not the case for the Atlantic source. The perturbations originating in the former describe the typical pathway of the tropical Northern Hemisphere pattern (Brönnimann 2007), and this signal might mask that from disturbances coming from the Gulf of Mexico. Third, other anomalous RWS appear in relation to ENSO such as those over the northeastern Pacific and the central tropical North Atlantic as already documented by previous studies (Toniazzo and Scaife 2006; Ayarzagüena et al. 2018). Again, these new RWSs are stronger than that over the Gulf of Mexico and their perturbations might contribute more to the total ENSO signal over Europe than the latter. Finally, the ray tracing shows different results in late winter from early winter, indicating that the background flow seasonality is also involved in the change of the wave train propagation. For instance, the perturbations of zonal wavenumber 3 originating over the Gulf of Mexico are not able to reach Europe in late winter, in contrast to the previous months.

Given that the intraseasonal shift in the North Atlantic SLP response was not reproduced in CMIP5 models, we have repeated the same analysis of anomalous RWS for those models to try to find a possible 

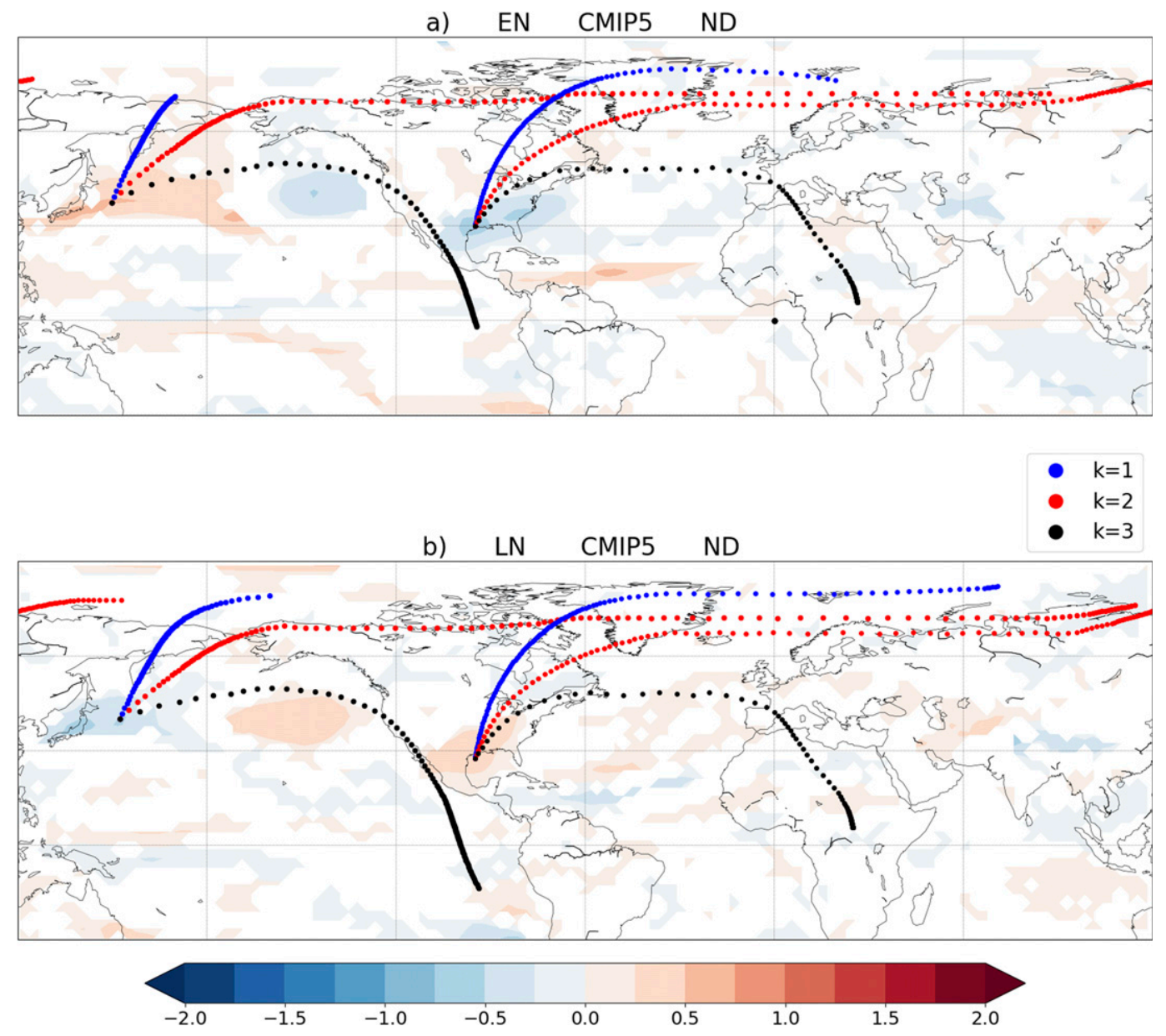

FIG. 6. RWSs are much weaker in coupled models than in observations. As in Figs. 5a and 5b, but for the multimodel mean of CMIP5 models. The RWS plotted correspond to those where at least $75 \%$ of models agree on sign with the multimodel mean.

different behavior respect to observations (Fig. 6). A quick look at these results reveals that coupled models reproduce a similar pattern of RWS in ND as in observations (Fig. 6). However, the intensity of the anomalies is much weaker. Similarly, the streamfunction does not show any strong structure over the North Atlantic and that is why is not included in the plot. An analysis of single model results reveals that this weak Atlantic signal is not an artifact of averaging realistic strength anomalies from different models that occur at slightly different locations, but the signal in each model is indeed very weak or even inexistent (not shown). Nevertheless, if strong sources were present, then ray tracing in Fig. 6 would suggest a similar propagation of Rossby waves as in observations. Thus, it seems that the differences in the teleconnection between free-running models and observations are not due to model bias in the background mean flow, in agreement with Scaife et al. (2017). Rather, a weak ENSO signal in RWS over the Gulf of
Mexico in model simulations is more likely to explain why models do not show the early winter Atlantic teleconnection.

We examine the origin of the anomalous RWS over the Gulf of Mexico in early winter. We first search for possible precipitation anomalies that might drive a change in RWS. Hence, Fig. 7 shows the anomalous precipitation in ND in the different datasets associated with EN and LN events. In addition to large positive anomalies over the equatorial Pacific, the EN events in JRA-55 show negative precipitation anomalies over the Caribbean Sea and positive over the Gulf of Mexico (Fig. 7a). These precipitation anomalies and the strong anomalous negative RWS over the Gulf of Mexico resemble the wet tropical eastern Pacific case in Scaife et al. (2017), and they reverse the sign for LN, albeit with weaker amplitude (Fig. 7b). They are also consistent with previous studies that documented that ENSOinduced SST anomalies over this area in fall are able 

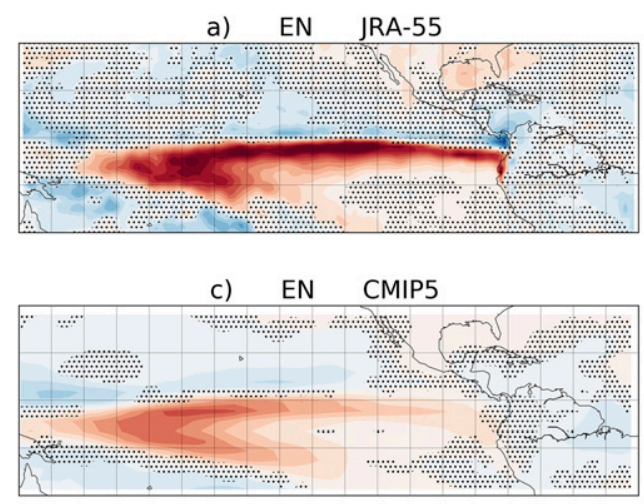

e) EN GloSea5

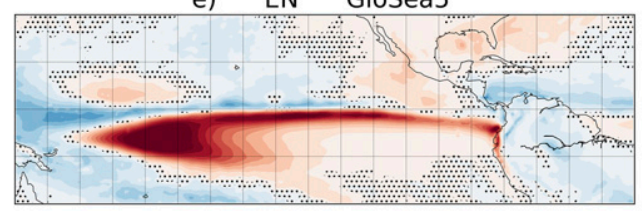

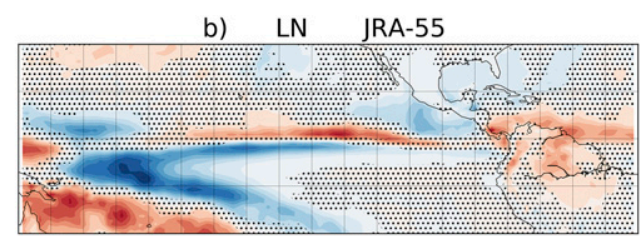
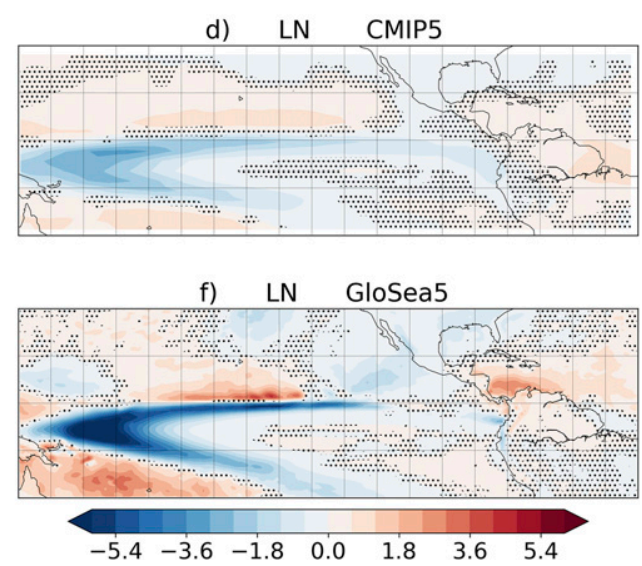

FIG. 7. ENSO-related precipitation anomalies appear over the Caribbean Sea and might be related to the anomalous RWS in that area. (a) Composite maps of anomalous precipitation ( $\mathrm{mm} \mathrm{day}^{-1}$ ) in ND for EN events in JRA-55. (b) As in (a), but for LN events. (c),(d) As in (a) and (b), but for the multimodel mean of CMIP5 models. (e),(f) As in (a) and (b), but for GloSea5. In this case nonstippled areas indicate statistically significant anomalies for JRA-55 and GloSea5, and robust values among CMIP5 models.

to induce large changes in convection due to the relatively warm base state in this season (Alexander and Scott 2002; Wang and Fiedler 2006). Additionally, the anomalous convection associated with the mentioned precipitation anomalies would change the upper-level divergent flow that encounters the increased vorticity of the jet, stimulating the RWS anomalies shown in Figs. 5a and 5b. Assuming these rainfall anomalies occur in response to Pacific rainfall changes through the meridional flow, the differences in the amplitude of the anomalies between EN and LN might be connected to the westward shift of the precipitation anomalies over the equatorial Pacific that Hoerling et al. (1997) detected for LN compared to EN.

In the case of CMIP5 simulations, similar results are found for rainfall as were found in the anomalous RWS field. The precipitation pattern over the Caribbean Sea and the Gulf of Mexico resembles that in reanalysis data, and this dipole can be identified for both EN and LN (Figs. 7c,d). However, the anomalies are much weaker than in JRA-55. Although the CMIP5 results in Figs. 7c and $7 \mathrm{~d}$ only display the multimodel mean, the intensity of the Gulf of Mexico-Caribbean Sea precipitation dipole is also weak in most individual models, and the SLP over the North Atlantic area in most cases does not show a robust ENSO signal in ND either (not shown). Provided the low amplitude of anomalies in most model results, it is difficult to establish a linear link between models' bias in Caribbean precipitation and ENSO response of the model in the North Atlantic. In this case, many other variability sources might affect both SLP and precipitation. In contrast, GloSea5 runs are able to simulate robust rainfall anomalies over the Caribbean Sea of similar magnitude (Figs. 7e,f) to those seen in the observations (Figs. 7a,b) and much stronger than seen in the CMIP5 models (Figs. 7c,d). As the initialized predictions also display the observed early winter ENSO signal in the North Atlantic, these results corroborate the link between tropical precipitation anomalies in early winter and the Atlantic SLP signal.

We can explain the differences in the ENSO signal in the precipitation pattern over the Caribbean Sea and Gulf of Mexico between free-running models and observations by following the same argument that we applied to the LN case in JRA-55 data. The equatorial Pacific precipitation anomalies are much weaker and westward shifted in CMIP5 models with respect to the JRA-55, which would result in weaker anomalies over the Gulf of Mexico and Caribbean Sea too. The differences in convection between observations and free-running models are closely linked to similar differences in the ENSO SST anomalies over the equatorial Pacific (Hoerling et al. 1997). Thus, the reason for 
disagreement between CMIP5 models and observations might be that the strength and the pattern of ENSO are biased (e.g., Bellenger et al. 2014).

\section{Summary and discussion}

Motivated by previous studies reporting a shift in the ENSO atmospheric response over NAE from early to late winter, we have investigated the pattern of influence in early winter. Our main conclusions are as follows:

- The EN SLP pattern in the northern extratropics in early winter is characterized by a wavelike structure that is symmetric about the equator in the Atlantic basin. In contrast, in late winter the EN pattern of SLP resembles a negative phase of the annular mode in the Northern Hemisphere, with little interhemispheric asymmetry.

- Except for small regional differences, the LN response is, in general, equal and opposite to EN.

- The intraseasonal shift in the ENSO winter signal is robust in different observational datasets in agreement with previous studies (e.g., Brönnimann et al. 2007; Fereday et al. 2008; King et al. 2018a). It is also captured in initialized climate predictions but not in free-running (CMIP5) simulations.

- The ENSO teleconnection to NAE in early winter does not appear to be influenced by the stratosphere where signals are weak in early winter. ENSO-related perturbations to precipitation anomalies over the Gulf of Mexico and Caribbean Sea seem responsible for the teleconnection to the North Atlantic.

- CMIP5 models show similar patterns of ENSOinduced anomalous Rossby wave sources over the Gulf of Mexico and precipitation anomalies in the Gulf of Mexico and Caribbean Sea. However, their amplitude is much weaker than in reanalysis data, consistent with the lack of an early winter ENSO signal over the North Atlantic in free-running models.

Our study constitutes a complement to previous work, particularly that by King et al. (2018b), who argued that more analysis is required to understand the ENSO teleconnections to the Euro-Atlantic sector in early winter. Indeed, the present study addresses some of the questions that King et al. (2018b) identified as outstanding topics to work on. One of them refers to the ability of coupled models to simulate the intraseasonal shift. A second one is related to the mechanisms involved in the teleconnections. In that sense, our results highlight the importance of ENSO-related disturbances originating over the Gulf of Mexico and Caribbean Sea for establishing the ENSO pattern of influence over the NAE in early winter. While Bladé et al. (2008) identified the SST anomalies over the tropical west Pacific and King et al. (2018a) pointed out a RWS over the northwest Pacific as the main precursors of the ENSO teleconnections in the Northern Hemisphere in early winter, we find that the ENSO teleconnection in the extratropical Atlantic appears to be more directly connected to tropical Atlantic signals generated by ENSO.

Together with King et al. (2018b), our study also constitutes a warning for seasonal-mean analysis since the ENSO teleconnection in the NAE evolves through the season. Seasonal averages might mask relevant processes that are only present in a certain month but not during the whole season.

Finally, the presence of this early winter teleconnection in initialized predictions and its absence in freerunning models suggest that model biases need to be corrected before this early winter signal is properly reproduced by current climate models.

Acknowledgments. B.A. and M.P.B. were supported by the Natural Environment Research Council Grant NE/M006123/1, the European Project 398 603557STRATOCLIM. B.A. was also funded by "Ayudas para la contratación de personal posdoctoral de formación en docencia e investigación en los departamentos de la Universidad Complutense de Madrid." S.I. was supported by the PRIMAVERA project, funded by the European Union's Horizon 2020 Programme, Grant Agreement 641727. A.S. and N.D. were supported by the Joint DECC/Defra Met Office Hadley Centre Climate Programme (GA01101). Japanese 55-year Reanalysis (JRA-55) project was carried out by the Japan Meteorological Agency (JMA) and the data were accessed through NCAR/UCAR Research Data Archive (https://rda.ucar.edu). Data from CMIP5 runs can be accessed through https://esgf-node.llnl.gov/search/cmip5/. Data from HadSLP2 and HadISST are available from the Met Office Hadley Centre via www.metoffice.gov.uk/ hadobs and the GloSea5 data used to produce the figures is available from the authors on request for research use only.

\section{REFERENCES}

Alexander, M., and J. Scott, 2002: The influence of ENSO on airsea interaction in the Atlantic. Geophys. Res. Lett., 29, 1701, https://doi.org/10.1029/2001GL014347.

Allan, R., and T. J. Ansell, 2006: A new globally complete monthly historical gridded mean sea level pressure dataset (HadSLP2): 1850-2004. J. Climate, 19, 5816-5842, https://doi.org/10.1175/ JCLI3937.1.

Ayarzagüena, B., J. López-Parages, M. Iza, N. Calvo, and B. Rodríguez-Fonseca, 2018: Stratospheric role in interdecadal changes of El Niño impacts over Europe. Climate Dyn., https://doi.org/10.1007/s00382-018-4186-3, in press. 
Bell, C. J., L. J. Gray, A. J. Charlton-Perez, M. M. Joshi, and A. A. Scaife, 2009: Stratospheric communication of El Niño teleconnections to European winter. J. Climate, 22, 4083-4096, https://doi.org/10.1175/2009JCLI2717.1.

Bellenger, H., E. Guilyardi, J. Leloup, M. Lengaigne, and J. Vialard, 2014: ENSO representation in climate models: From CMIP3 to CMIP5. Climate Dyn., 42, 1999-2018, https:// doi.org/10.1007/s00382-013-1783-z.

Bladé, I., M. Newman, M. A. Alexander, and J. D. Scott, 2008: The late fall extratropical response to ENSO: Sensitivity to coupling and convection in the tropical west Pacific. J. Climate, 21, 6101-6118, https://doi.org/10.1175/2008JCLI1612.1.

Brönnimann, S., 2007: Impact of El Niño-Southern Oscillation on European climate. Rev. Geophys., 45, RG3003, https://doi.org/ 10.1029/2006RG000199.

_ - E. Xoplaki, C. Casty, A. Pauling, and J. Luterbacher, 2007: ENSO influence on Europe during the last centuries. Climate Dyn., 28, 181-197, https://doi.org/10.1007/s00382-006-0175-z.

Butler, A. H., L. M. Polvani, and C. Deser, 2014: Separating the stratospheric and tropospheric pathways of El Niño-Southern oscillation teleconnections. Environ. Res. Lett., 9, 024014, https://doi.org/10.1088/1748-9326/9/2/024014.

Cagnazzo, C., and E. Manzini, 2009: Impact of the stratosphere on the winter tropospheric teleconnections between ENSO and the North Atlantic and European region. J. Climate, 22, 12231238, https://doi.org/10.1175/2008JCLI2549.1.

Davey, M. K., A. Brookshaw, and S. Ineson, 2014: The probability of the impact of ENSO on precipitation and near-surface temperature. Climate Risk Manage., 1, 5-24, https://doi.org/ 10.1016/j.crm.2013.12.002.

Deser, C., I. R. Simpson, K. A. McKinnon, and A. S. Phillips, 2017: The Northern Hemisphere extratropical atmospheric circulation response to ENSO: How well do we know it and how do we evaluate models accordingly? J. Climate, 30, 5059-5082, https://doi.org/10.1175/JCLI-D-16-0844.1.

Dufresne, J.-L., and Coauthors, 2013: Climate change projections using the IPSL-CM5 Earth system model: From CMIP3 to CMIP5. Climate Dyn., 40, 2123-2165, https://doi.org/10.1007/ s00382-012-1636-1.

Dunstone, N., D. Smith, A. Scaife, L. Hermanson, R. Eade, N. Robinson, M. Andrews, and J. Knight, 2016: Skillful predictions of the winter North Atlantic Oscillation one year ahead. Nat. Geosci., 9, 809-814, https://doi.org/10.1038/ ngeo2824.

Fereday, D. R., J. R. Knight, A. A. Scaife, C. K. Folland, and A. Philipp, 2008: Cluster analysis of North Atlantic-European circulation types and links with tropical Pacific sea surface temperatures. J. Climate, 21, 3687-3703, https://doi.org/10.1175/2007JCLI1875.1.

Fogli, P. G., and Coauthors, 2009: INGV-CMCC Carbon (ICC): A carbon cycle Earth system model. CMCC Research Paper, Bologna, Italy, 31 pp., https://www.cmcc.it/publications/rp0061ingv-cmcc-carbon-icc-a-carbon-cycle-earth-system-model.

García-Herrera, R., N. Calvo, R. R. García, and M. A. Giorgetta, 2006: Propagation of ENSO temperature signals into the middle atmosphere: A comparison of two general circulation models and ERA-40 reanalysis data. J. Geophys. Res., 111, D06101, https://doi.org/10.1029/2005JD006061.

García-Serrano, J., C. Cassou, H. Douville, A. Giannini, and F. J. Doblas-Reyes, 2017: Revisiting the ENSO-teleconnection to the tropical North Atlantic. J. Climate, 30, 6945-6957, https:// doi.org/10.1175/JCLI-D-16-0641.1.

Giorgetta, M. A., and Coauthors, 2013: Climate and carbon cycle changes from 1850 to 2100 in MPI-ESM simulations for the
Coupled Model Intercomparison Project phase 5. J. Adv. Model. Earth Syst., 5, 572-597, https://doi.org/10.1002/ jame.20038.

Ham, Y.-G., M.-K. Sung, S.-I. An, S. D. Schubert, and J.-S. Kug, 2014: Role of Tropical Atlantic SST variability as a modulator of El Niño teleconnections. Asia-Pac. J. Atmos. Sci., 50, 247-261, https://doi.org/10.1007/s13143-014-0013-x.

Hoerling, M. P., A. Kumar, and M. Zhong, 1997: El Niño, La Niña, and the nonlinearity of the teleconnections. J. Climate, $\mathbf{1 0}$, 1769-1786, https://doi.org/10.1175/1520-0442(1997)010<1769: ENOLNA $>2.0 . \mathrm{CO} ; 2$.

Horel, J. D., and J. M. Wallace, 1981: Planetary-scale atmospheric phenomena associated with the Southern Oscillation. Mon. Wea. Rev., 109, 813-829, https://doi.org/10.1175/ 1520-0493(1981)109<0813:PSAPAW > 2.0.CO;2.

Hurrell, J., and Coauthors, 2013: The Community Earth System Model: A framework for collaborative research. Bull. Amer. Meteor. Soc., 94, 1339-1360, https://doi.org/10.1175/ BAMS-D-12-00121.1.

Ineson, S., and A. A. Scaife, 2009: The role of the stratosphere in the European climate response to El Niño. Nat. Geosci., 2, 32-36, https://doi.org/10.1038/ngeo381.

Iza, M., N. Calvo, and E. Manzini, 2016: The stratospheric pathway of La Niña. J. Climate, 29, 8899-8914, https://doi.org/10.1175/ JCLI-D-16-0230.1.

Japan Meteorological Agency, 2013: JRA-55: Japanese 55-year reanalysis, monthly means and variances. Research Data Archive at the National Center for Atmospheric Research, accessed 28 June 2017, https://doi.org/10.5065/D60G3H5B.

Jiménez-Esteve, B., and D. I. V. Domeisen, 2018: The tropospheric pathway of the ENSO-North Atlantic teleconnection. J. Climate, 31, 4563-4584, https://doi.org/10.1175/JCLI-D-17-0716.1.

King, M. P., I. Herceg-Bulić, F. Kucharski, and N. Keenlyside, 2018a: Interannual tropical Pacific sea surface temperature anomalies teleconnection to Northern Hemisphere atmosphere in November. Climate Dyn., 50, 1881-1899, https:// doi.org/10.1007/s00382-017-3727-5.

- — - I. Bladé, J. García-Serrano, N. Keenlyside, F. Kucharski, C. Li, and S. Sobolowski, 2018b: Importance of late fall ENSO teleconnection in the Euro-Atlantic sector. Bull. Amer. Meteor. Soc., 99, 1337-1343, https://doi.org/ 10.1175/BAMS-D-17-0020.1.

Kobayashi, S., and Coauthors, 2015: The JRA-55 reanalysis: General specifications and basic characteristics. J. Meteor. Soc. Japan, 93, 5-48, https://doi.org/10.2151/jmsj.2015-001.

Lin, H., J. Derome, and G. Brunet, 2007: The nonlinear transient atmospheric response to tropical forcing. J. Climate, $\mathbf{2 0}$, 5642-5665, https://doi.org/10.1175/2007JCLI1383.1.

Lin, P., Q. Fu, and D. L. Hartmann, 2012: Impact of tropical SST on stratospheric planetary waves in the Southern Hemisphere. J. Climate, 25, 5030-5046, https://doi.org/10.1175/ JCLI-D-11-00378.1.

MacLachlan, C., and Coauthors, 2015: Global Seasonal forecast system version 5 (GloSea5): A high-resolution seasonal forecast system. Quart. J. Roy. Meteor. Soc., 141, 1072-1084, https://doi.org/10.1002/qj.2396.

Manzini, E., M. A. Giorgetta, M. Esch, L. Kornblueh, and E. Roeckner, 2006: The influence of sea surface temperatures on the Northern winter stratosphere: Ensemble simulations with the MAECHAM5 model. J. Climate, 19, 3863-3881, https://doi.org/10.1175/JCLI3826.1.

- C. Cagnazzo, P. G. Fogli, A. Bellucci, and W. A. Muller, 2012: Stratosphere-troposphere coupling at inter-decadal time 
scales: Implications for the North Atlantic Ocean. Geophys. Res. Lett., 39, L05801, https://doi.org/10.1029/2011GL050771.

Met Office Hadley Center, 2003: Hadley Centre Sea Ice and Sea Surface Temperature data set (HadISST). Met Office Hadley Centre for Climate Change Host, accessed 4 October 2016, https://www.metoffice.gov.uk/hadobs/hadisst/data/ download.html.

_ 2005: Hadley Centre Sea Level Pressure data set (HadSLP2). Met Office Hadley Centre for Climate Change Host, accessed 4 October 2016, https://www.metoffice.gov.uk/hadobs/hadslp2/ data/download.html.

Moron, V., and I. Gouirand, 2003: Seasonal modulation of the ENSO relationship with sea level pressure anomalies over the North Atlantic in October-March 1873-1996. Int. J. Climatol., 23, 143-155, https://doi.org/10.1002/joc.868.

Peixoto, J. P., and A. H. Oort, 1992: Physics of Climate. Springer, $520 \mathrm{pp}$.

Polvani, L. M., L. Sun, A. H. Butler, J. H. Richter, and C. Deser, 2017: Distinguishing stratospheric sudden warmings from ENSO as key drivers of wintertime climate variability over the North Atlantic and Eurasia. J. Climate, 30, 1959-1969, https:// doi.org/10.1175/JCLI-D-16-0277.1.

Rayner, N. A., D. E. Parker, E. B. Horton, C. K. Folland, L. V. Alexander, D. P. Rowell, E. C. Kent, and A. Kaplan, 2003: Global analyses of sea surface temperature, sea ice, and night marine air temperature since the late nineteenth century. J. Geophys. Res., 108, 4407, https://doi.org/10.1029/ 2002JD002670.

Sardeshmukh, P., and B. J. Hoskins, 1988: The generation of global rotational flow by steady idealized tropical divergence. J. Atmos. Sci., 45, 1228-1251, https://doi.org/10.1175/ 1520-0469(1988)045<1228:TGOGRF $>2.0$. CO;2.

Scaife, A. A., and Coauthors, 2014: Skillful long-range prediction of European and North American winters. Geophys. Res. Lett., 41, 2514-2519, https://doi.org/10.1002/2014GL059637.
- and Coauthors, 2017: Tropical rainfall, Rossby waves and regional winter climate predictions. Quart. J. Roy. Meteor. Soc., 143, 1-11, https://doi.org/10.1002/qj.2910.

Toniazzo, T., and A. A. Scaife, 2006: The influence of ENSO on winter North Atlantic climate. Geophys. Res. Lett., 33, L24704, https://doi.org/10.1029/2006GL027881.

Vichi, M., E. Manzini, P. Fogli, A. Alessandri, L. Patara, E. Scoccimarro, S. Masina, and A. Navarra, 2011: Global and regional ocean carbon uptake and climate change: sensitivity to a substantial mitigation scenario. Climate Dyn., 37, 19291947, https://doi.org/10.1007/s00382-011-1079-0.

Volodin, E., N. Dianskii, and A. Gusev, 2010: Simulating present-day climate with the INMCM4.0 coupled model of the atmospheric and oceanic general circulations. Izv., Atmos. Ocean. Phys., 46, 414-431, https://doi.org/10.1134/ S000143381004002X.

Wang, C., 2002: Atlantic climate variability and its associated atmospheric circulations cells. J. Climate, 15, 1516-1536, https:// doi.org/10.1175/1520-0442(2002)015<1516:ACVAIA > 2.0.CO;2.

_ tropical Pacific: A review. Prog. Oceanogr., 69, 239-266, https://doi.org/10.1016/j.pocean.2006.03.004.

Watanabe, S., and Coauthors, 2011: MIROC-ESM: Model description and basic results of CMIP5-20c3m experiments. Geosci. Model Dev., 4, 845-872, https://doi.org/10.5194/ gmd-4-845-2011.

Williams, K. D., and Coauthors, 2015: The Met Office Global Coupled model 2.0 (GC2) configuration. Geosci. Model Dev., 8, 1509-1524, https://doi.org/10.5194/gmd-8-1509-2015.

Yukimoto, S., 2011: Meteorological Research Institute Earth System Model version 1 (MRI-ESM1): Model description. MRI. Tech. Rep. 64, 88 pp.

Zubiaurre, I., and N. Calvo, 2012: The El Niño-Southern Oscillation (ENSO) Modoki signal in the stratosphere. J. Geophys. Res., 117, D04104, https://doi.org/10.1029/2011JD016690. 